\title{
Integrated Accident Prevention Detection and Response System (IAPDRS)
}

\author{
Vivek Upadhyay, Simran Gupta, Snigdha Chaturvedi, Dhirendra Singh
}

\begin{abstract}
The Vehicle Industry is ascending with enduring development throughout the world. Hence, there is a high plausibility of growth in individuals getting their vehicles. Although various well-being measures are being utilized to make the framework of the vehicle significantly more adaptable, there is still a vast void in the post-accident reporting centers. Road accidents are inevitable, but many lives can be spared if the emergency services with appropriate data and help are provided in time. The proposed model offers another way to deal with this issue. Also, this paper presents a prevention method to avoid accidents occurred due to unnoticed speed breakers, blind turns, pits, stop signs etc.
\end{abstract}

Keywords: Accident Detection and Prevention, Blind Turn Detection, Global Positioning System, Global System for Mobile, Internet of Things, Radio Frequency Identification.

\section{INTRODUCTION}

$\mathrm{I}_{\mathrm{n}}$ In the current scenario, car accidents would be reduced with the usage of this impelled life-saving measure. As status report on road safety, India drives the world in street accidents. In the year 2016, over 0.3 million individuals were a casualty of street accidents in India. The WHO reports, street activity wounds caused an expected 1.35 million deaths worldwide in the year 2016. Only five countries, representing 144.3 million individuals, have laws that meet best practices for all five key risk factors (speeding, drink-driving, helmets, safety belts, and child limitations) [1]. Over 33\% of street movement death in low and center wage nations is among people on foot and cyclists. Be that as it may, fewer than $35 \%$ of low and center pay nations have arrangements set up to ensure these street incidents. A National Crime Records Bureau report uncovered that consistently, more than 135,000 car accidentrelated deaths happen in the country [2]. This research aims to develop Quick Emergency Response, sparing time to treat the accident casualties and to help protect the group from achieving the spot-on time. This paper presents a novel method for detecting and reporting a road accident, which also focuses on the prevention of an accident due to speed breakers.

Revised Manuscript Received on February 05, 2020.

* Correspondence Author

Vivek Upadhyay*, Department of Computer Science and Engineering, Maulana Azad National Institute of Technology, Bhopal, India.

Simran Gupta, Department of Computer Science and Engineering, Maulana Azad National Institute of Technology, Bhopal, India.

Snigdha Chaturvedi, Department of Computer Science and Engineering, Maulana Azad National Institute of Technology, Bhopal, India.

Dhirendra Singh, Assistant Professor, Department of Computer Science and Engineering, Maulana Azad National Institute Technology, Bhopal, India.

(c) The Authors. Published by Blue Eyes Intelligence Engineering and Sciences Publication (BEIESP). This is an open access article under the CC BY-NC-ND license (http://creativecommons.org/licenses/by-nc-nd/4.0/) indicated by the World Health Organization's (WHO) global

The proposed design has many benefits like low cost, portability, small size. Also proposed model doesn't require any external electricity supply to detect speed breaker, blind turns, pits, stop signs, etc. This paper proposes a model to give security in minimal effort more effectively than the existing system and models.

\section{RELATED WORK}

After seeing the rapid growth in accident rates, government, along with various organizations, are trying to find the solutions to reduce the road accidents. These organizations are using the Internet of Things (IoT) to solve such problems. Using IoT methodologies are developed for realtime health care and monitoring, sensors are used to capture data, and compared with a threshold (set by experts) using micro-controller. If the reading from the sensor crosses a certain threshold, then the location of the accident site will be sent to nearby emergency services. Road accident detection system proposed in $[8,12]$ uses sensors that were only able to cover limited angles (e.g., only able to detect collision from front or back). There are other possibilities of an accident that are not included in the existing system like a car can topple, or there can be a fire inside the vehicle. In [11], the authors used google maps to detect the location of an accident that requires internet connectivity. Due to this, the idea of an alert system that senses the accident and its seriousness to alert the nearby medical center for providing ambulance or medical aid to the accident area comes up in [6].

But existing systems have not focused on an accident that can occur during nighttime or in rainy season due to blind turns, pits, stop signs or speed breakers. Also, these systems don't account for an accident caused due to fire, that is rare to happen, but they are happening.

This paper proposes a novel model which removes the shortcomings associated with existing road accident detection systems, which in result will help in decreasing the number of road accidents due to different scenarios presented in this paper.

\section{PROPOSED DESIGN}

The objective of this paper is to develop a system that can detect and report an accident. Also, this paper provides a method to prevent an accident because of a speed breaker, blind turns, pits, stop signs, etc. Our prototype, named as Integrated Accident Prevention Detection and Response System (IAPDRS) includes a GPS module to locate accident site, and to report the accident to nearby emergency services, we have included GSM module as shown in Figure. 1. The system develops the reporting of the accident and the time induced in it $[13,14]$. 


\section{Integrated Accident Prevention Detection and Response System (IAPDRS)}

Our proposed model is designed in such a way that whenever an accident occurs, Emergency contact services like relatives, police, fire brigade, etc. will be notified immediately $[7,10]$.

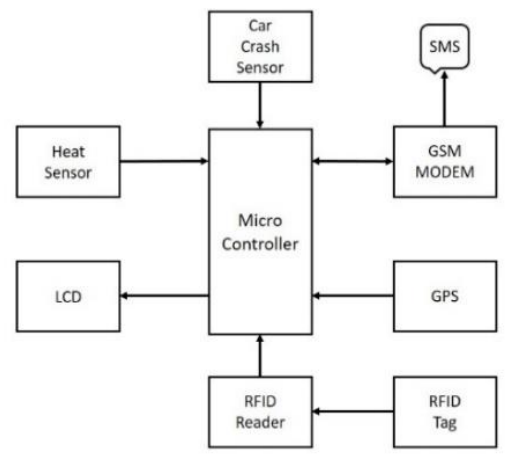

Fig. 1 System Design of the Proposed model

It requires sensors which read the pressure applied on the car during an accident from four corners and also from the top if the car gets toppled and heat sensor which measures the temperature of the surroundings and if the heat generated during an accident it will detect the sudden increment in temperature. This framework utilizes crash switches as sensors which are placed on four sides of the car and roof of the car in case the car gets toppled, so whenever an accident occurs, the pressure exerted is distinguished by utilizing crash collision switch. This component continuously sends signals to micro-controller whenever the switch is turned on by applied pressure. When micro-controller receives the data, it starts the 60 -second timer to find out whether the driver is in a good state [3]. The timer gives the driver a chance to regain his senses. And in case of a minor accident, he/she can stop the system from calling emergency services [4].

As described earlier, the heat sensor is placed in the car to measure temperature continuously and fed to the microcontroller [15]. When the temperature reaches a specific value, it shows that the accident is occurred due to which heat is generated. Figure. 2 shows the complete prototype of the proposed model used in this research.

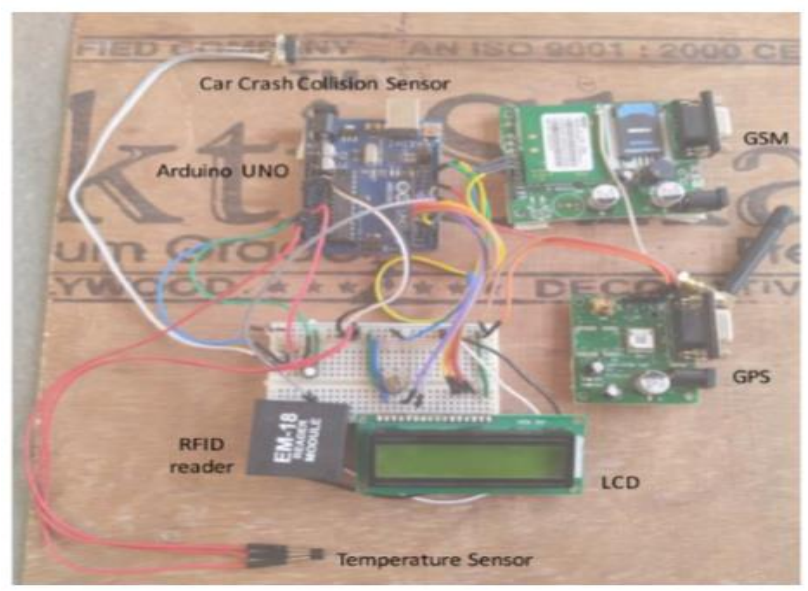

Fig. 2 Prototype of Proposed Design

\section{ADDITIONAL FEATURE}

As we know that these days due to. rash driving, people forget to take note of speed breakers, pits, stop signs, etc. on the lanes and also during night hours because of low visibility speed breakers, pits, stop signs, blind turns, etc. are unknown to the drivers. As a result, all these reasons cause an accident to occur. Speed breakers are built for safety purpose, but due to the irresponsible behavior of the drivers, it leads to a disaster [9]. The proposed design avoids an accident by alerting the driver about the speed breaker, pits, stop signs, blind turns, etc. beforehand, so he takes note of that and slows down his vehicle during the day as well in night hours. The proposed model uses radiofrequency waves to establish communication between the speed breaker and the vehicle. Speed breakers are simply attached to a radio frequency tag and vehicle is connected to radio frequency reader [5]. When any speed breaker meets the car, then the alarm is generated on the displaying device of the car. A lot of RFID tag-reader combinations are available based on the range of contact. This will be a very fruitful feature when we are driving at night.

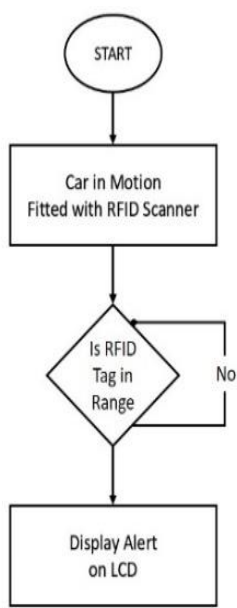

Fig. 3 Flowchart of prevention System

To implement this feature, the proposed model uses EM-18 RFID Reader. The reader, when is in the proximity of the tag, will give an alert to the driver via the LCD screen as depicted in Figure. 3. The vehicle should be fitted with an RFID reader, and the RFID tag is attached to a speed breaker. Whenever the vehicle comes in a certain range, LCD will show an alert message, which in result will help the driver to slow down the vehicle.
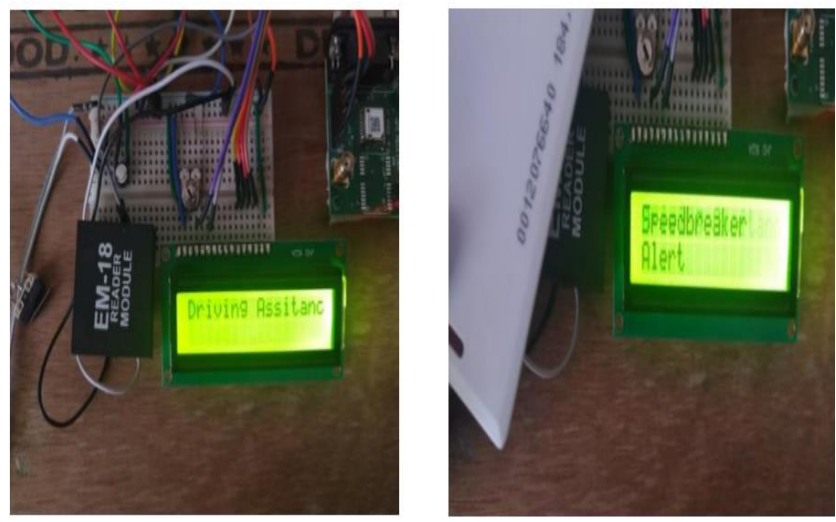

Fig. 4 Working of RFID for speed-breaker detection

Published By:

Retrieval Number: C5190029320/2020@BEIESP

Blue Eyes Intelligence Engineering \& Sciences Publication 
Figure. 4 shows the working of RFID for speed-breaker detection, speed breaker alert is shown in LCD screen whenever the vehicle comes in a certain range with speed breaker. Similarly, alerts for blind turn, pits, the signboard is being displayed using different combinations of RFID tagreader [9].

\section{RESULT ANALYSIS}

The testing is done on different locations of a confined area and as a result whenever an accident is occurred SMS is sent to saved number in the program. Whenever the system is switched on and an accident is occurred then it sends SMS to the predefined number. The SMS is received in the format of DMM (Degree and Decimal Minutes). This SMS consist of a text message alerting with words "ACCIDENT OCCURRED-NEED AMBULANCE" following with exact location of the prototype with defined latitude and longitude.
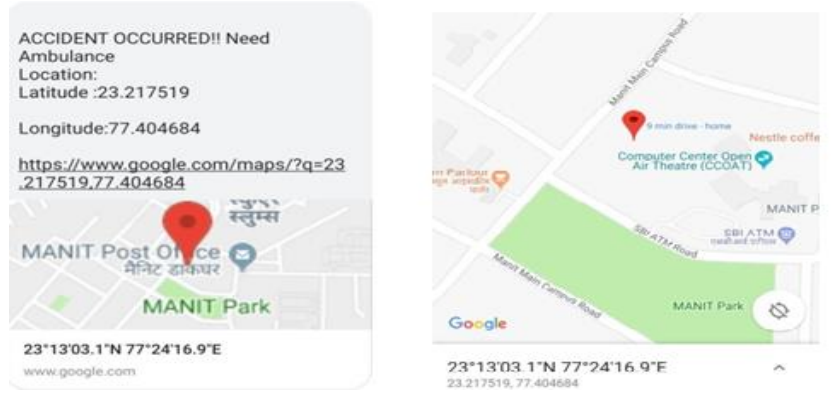

Fig.5 Livesite testing picture

As depicted in figure. 5, whenever an accident occurs the proposed system can detect accident and reporting to nearby emergency service. But there are times, proposed model fails like in heavy rain or remote areas where GSM and GPS stops working.

\section{CONCLUSION}

This paper gives a design which has many benefits like low cost, portability, small size. It also proposes an interactive environment in which the vehicle can communicate with the surroundings to warn the driver with any hazards or alerts and simultaneously facilitate communication on behalf of the user in case he loses consciousness with emergency systems. Using the proposed method, the presence of blind turns, pits, stop signs, etc. can be detected easily. As a result, this will contribute to a significant reduction in road accidents.

\section{FUTURE SCOPE}

The design presented in this paper can be extended to a solution for communication in no network areas or where the GPS fails, such as rural area, tunnels, off-road accidents. A basic idea could be to use FM communication between transmitter and receiver. This will empower the vehicle by giving it an alternate source of communication when there is no network. A wireless webcam can be added in this for capturing the images which will help in assisting the driver. Also, we can use the above wireless method to communicate nearby vehicles.

\section{REFERENCES}

1. WHO (2018), Global Status Report on Road Safety,
2. Available:

https://www.who.int/violence_injury_prevention/road_safety_status/2 018/en/

3. SIAM (2014), Society for Automotive Fitness \& Environment (SAFE), Available: http://www.siam.in/uploads/filemanager/1safe_SAFEAnnual-Report2013-14.pdf

4. N. Ilakkiya, C. Mallika, A. Hema, and S. Visalatchy, "Automatic Vehicle Accident Recognition and Messaging system by Use of GSM and GPS Modem," International Journal of Advanced Scientific Research \& Development (IJASRD), Vol. 4, no. 11, pp. 63- 68, Nov. 2017.

5. K. Goh, J. Jaafar, E. Mustapha, and E. Goh, "Automatic accident location detection system (AALDS)," in Proc. 4th World Congress on Information and Communication Technologies (WICT), Malaysia, 2014

6. S. Kubota, Y. Okamoto, and H. Oda, "Safety Driving Support System Using RFID for Prevention of Pedestrian-involved Accidents," in Proc. 6th International Conference on ITS Telecommunications, China, 2006.

7. D. Tushara, and P. Vardhini, "Wireless vehicle alert and collision prevention system design using Atmel microcontroller," in Proc. International Conference on Electrical, Electronics, and Optimization Techniques (ICEEOT), India, 2016.

8. K. Meena, C. Amuthadevi, and G. Kumar, "Internet of Things based Accident Prevention and Detection System," International Journal of Engineering \& Technology, Vol. 7, no. 2.4, pp. 85-87, Feb. 2018.

9. K. Manogna, J. Chandra, and V. Ratnam, "Implementation of IoT based vehicle theft detection and accident monitoring system using Arduino," International Journal of Engineering \& Technology, Vol. 7, no. 27, pp. 331-334, March 2018.

10. N. Jeevagan, P. Santosh, R. Berlia, and S. Kandoi, (2014, October), "RFID based vehicle identification during collisions," in Proc. IEEE Global Humanitarian Technology Conference (GHTC), USA, 2014

11. K. Poorani, A. Sharmila, G. Sujithra, and P. Swetha, "IoT based live streaming of vehicle, position accident prevention, and detection system," International Journal of Recent Trends in Engineering and Research, Vol. 3, no. 3, pp. 52-55 April 2017.

12. M. Desima, P. Ramli, D. Ramdani, and S. Rahman, "Alarm system to detect the location of IoT-based public vehicle accidents," in Proc. International Conference on Computing, Engineering, and Design (ICCED), Malaysia, 2017.

13. K. Goh, Y. Chen, and D. Arumugam, "Road Accident Auto-dialer via Pressure Sensor," in Proc. Human-Computer Interaction International - Posters' Extended Abstract - Communications in Computer and Information Science, USA, 2013.

14. J. White, C. Thompson, H. Turner, B. Dougherty, and C. Schmidt, "WreckWatch: Automatic traffic accident detection and notification with smartphones," Journal of Mobile Networks and Applications, Vol. 16, no. 3, pp. 285-303, March 2011.

15. S. Sonika, K. Sathiyasekar, and S. Jaishree, "Intelligent accident identification system using GPS, GSM modem," International Journal of Advanced Research in Computer and Communication Engineering, Vol. 3, no. 2, pp. 5487-5489, Feb. 2014.

16. M. Reddy, and K. Rao, "Fire Accident Detection and Prevention Monitoring System using Wireless Sensor Network-enabled Android Application," Indian Journal of Science and Technology, Vol. 9, no. 17, pp. 1-5, May 2016.

\section{AUTHOR PROFILE}

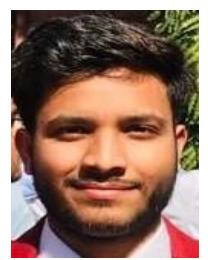

Vivek Upadhyay was born in Gwalior, India in 1997. $\mathrm{He}$ is currently pursuing bachelor's degree in Computer Science and Engineering from Maulana Azad National Institute of Technology, Bhopal, India. His research interests include Machine Learning, IoT, Natural Language Processing and Pattern Recognition.

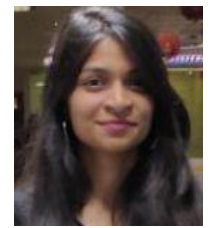

Simran Gupta was born in Alwar, Rajasthan in 1996. She completed her bachelor's degree in Computer Science and Engineering from Maulana Azad National Institute of Technology. Her interest lies in Machine Learning, IOT, Natural Language Processing.

Published By:

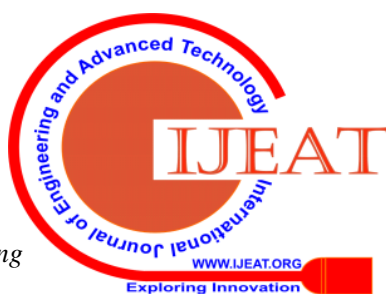


Snigdha Chaturvedi was born in Kuwait. She did her schooling with IHS Dubai and completed her bachelor's degree in Computer Science and Engineering from Maulana Azad National Institute of Technology, Bhopal, India. Her research interests include Machine Learning, Natural Language Processing and IOT.

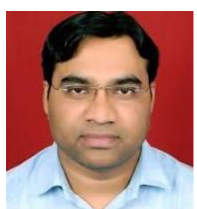

Dhirendra Singh has received his $\mathrm{PhD}$ degree in computer science and engineering from the Maulana Azad National Institute Technology, Bhopal, India in 2015. After his Post graduation, he has worked as Software Developer in NIIT Technologies Ltd., New Delhi, India. Currently he is working as Assistant Professor in the department of Computer Science and Engineering, Maulana Azad National Institute Technology, Bhopal, India. He has more than 12 years of experience of industry, teaching and research. His research interests include Graph Theory, Parallel algorithms, Image processing and Machine learning. 